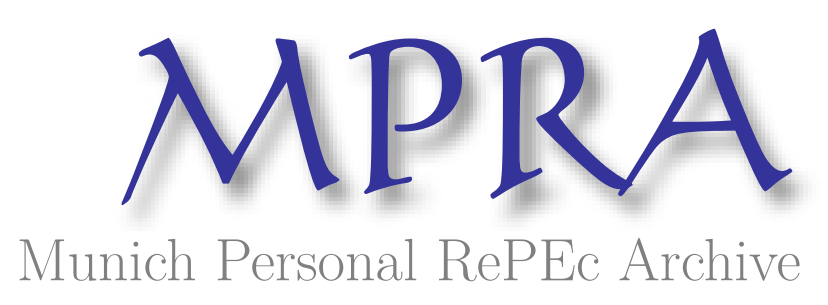

\title{
Collateral in Banking Policy and Adverse Selection
}

Gilroy, Bernard Michael and Broll, Udo

1986

Online at https://mpra.ub.uni-muenchen.de/18709/

MPRA Paper No. 18709, posted 18 Nov 2009 10:39 UTC 


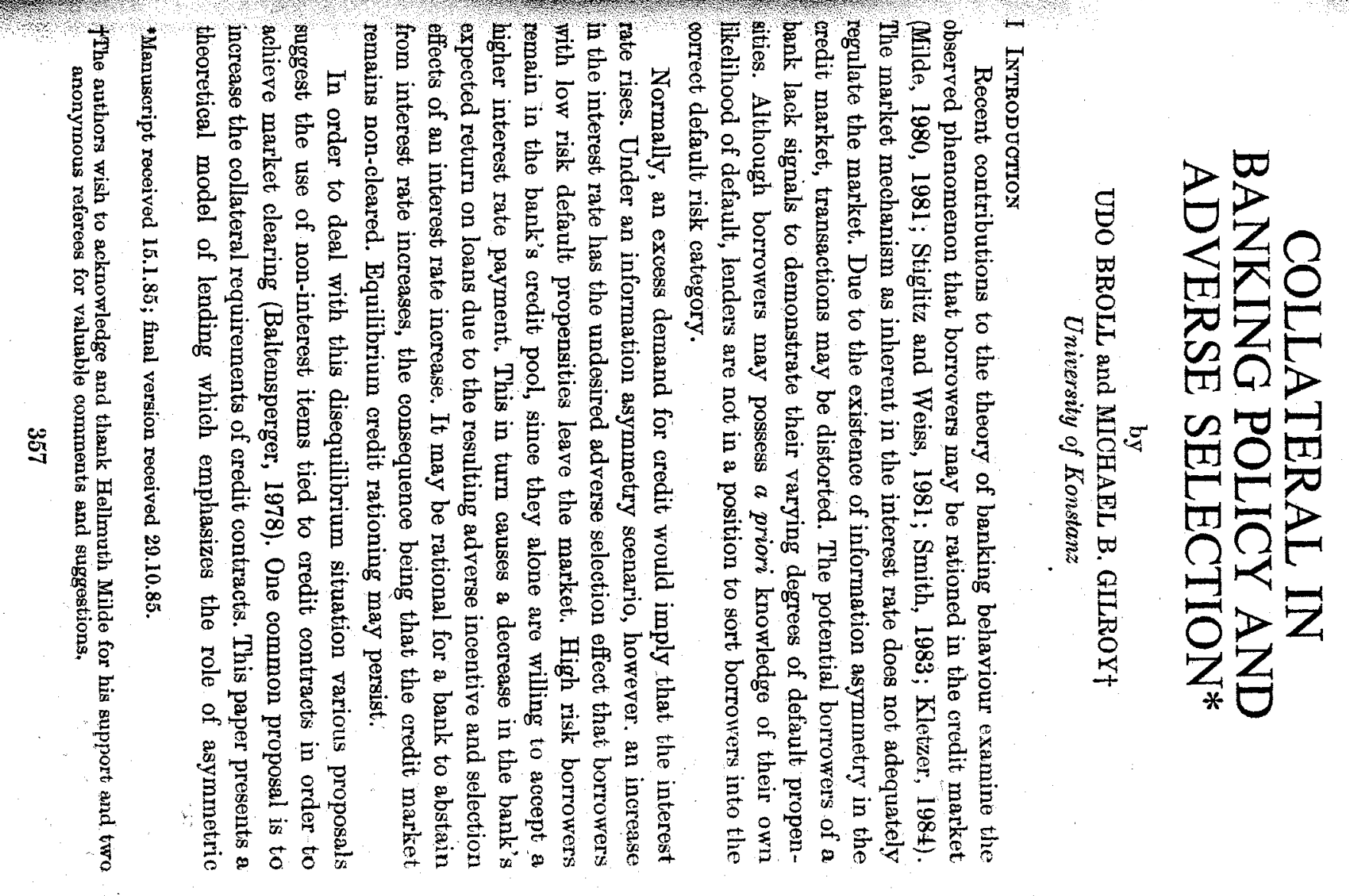





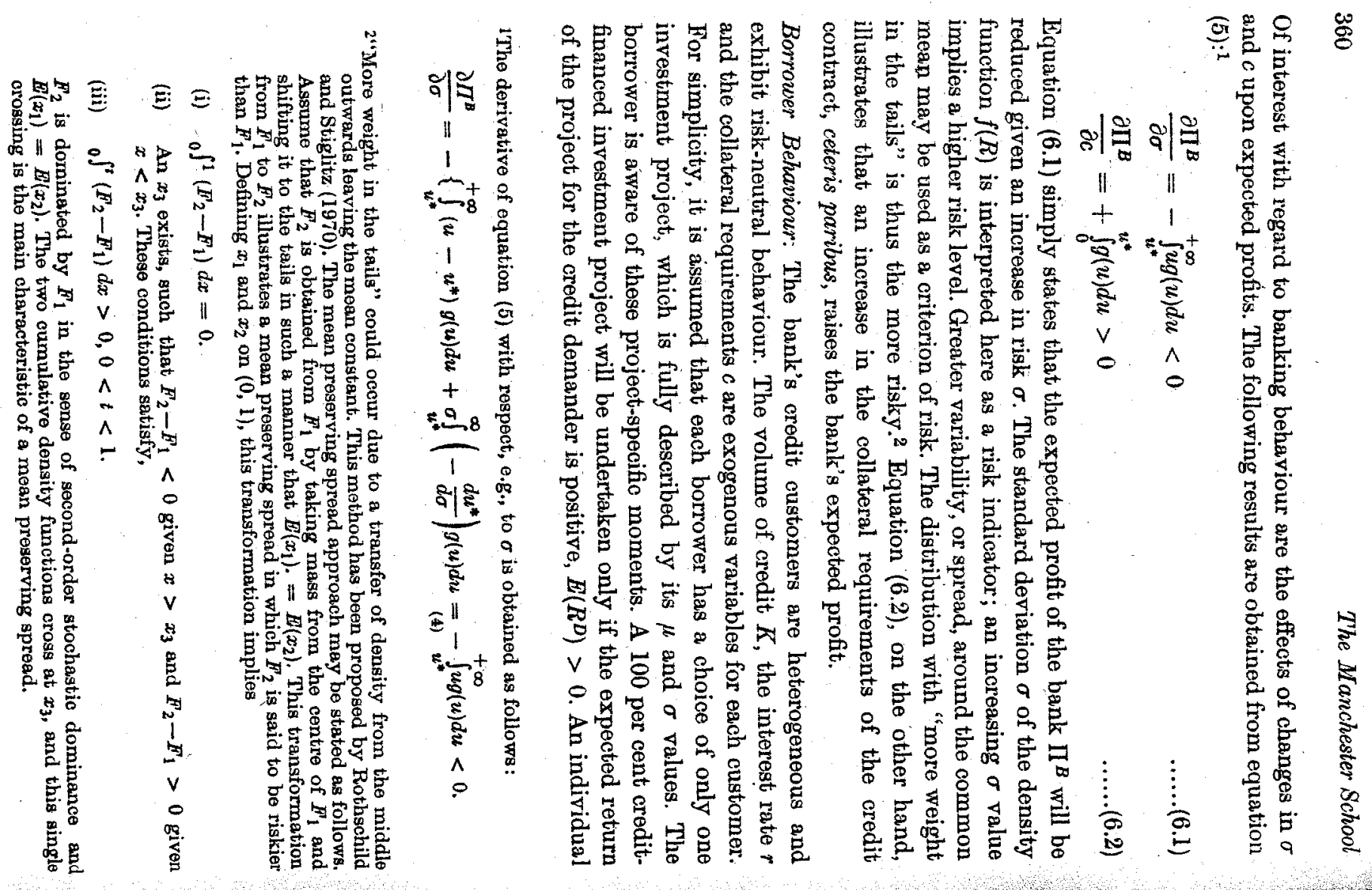



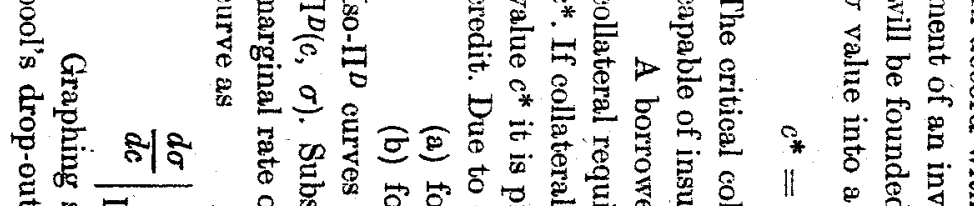

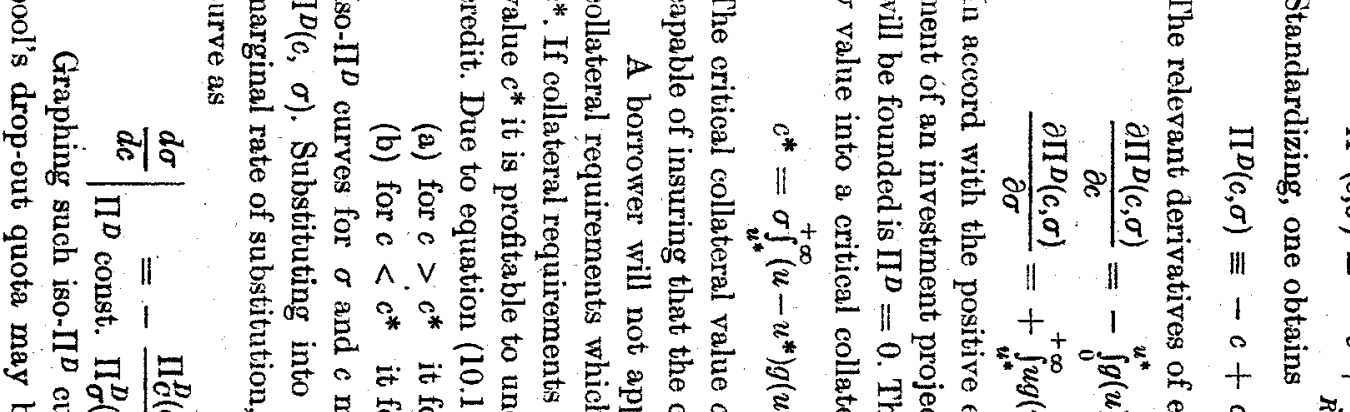



ง

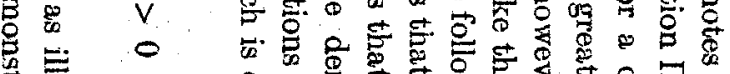

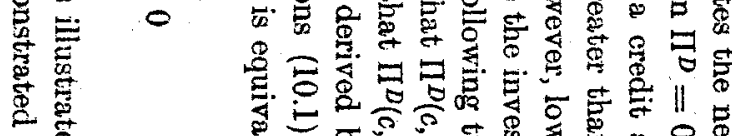



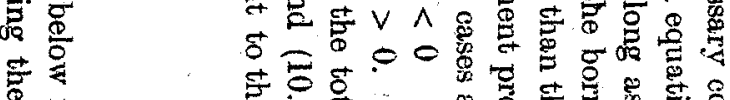

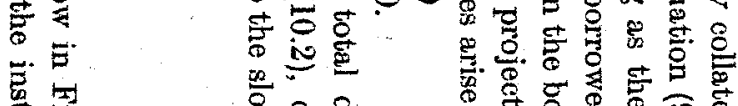

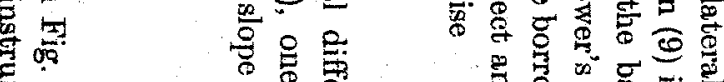

5 क क

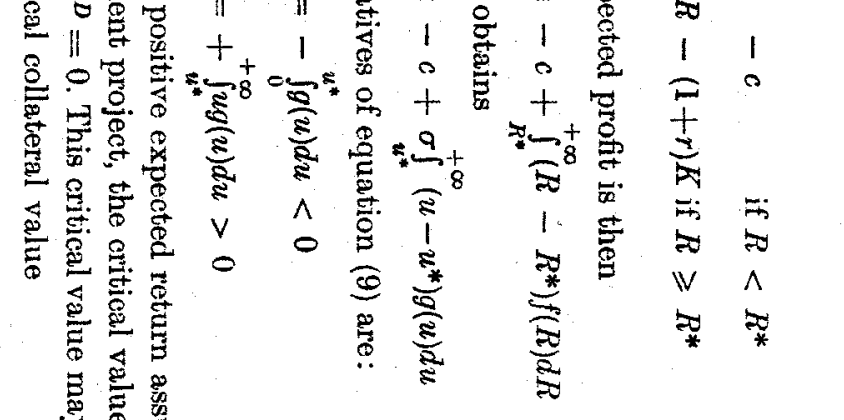

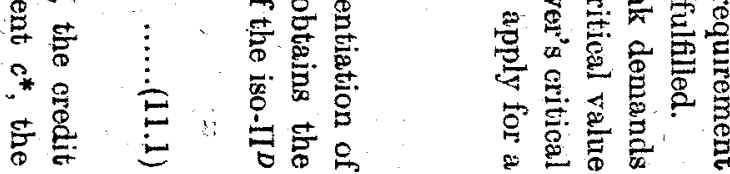

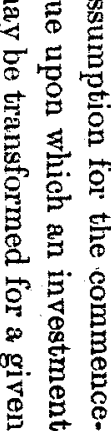

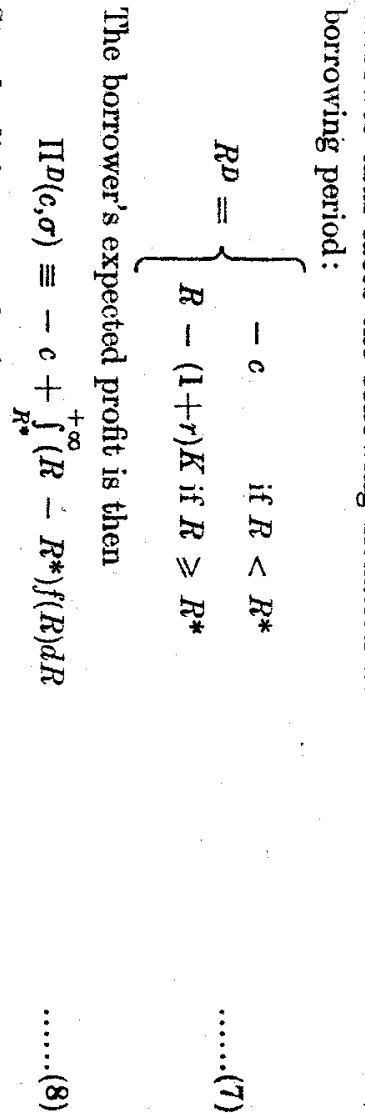

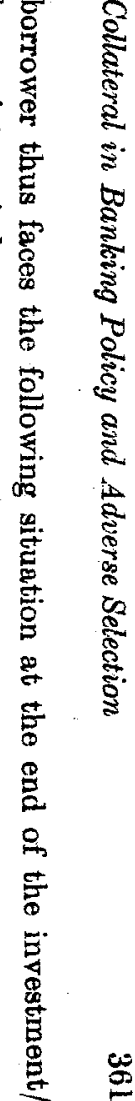



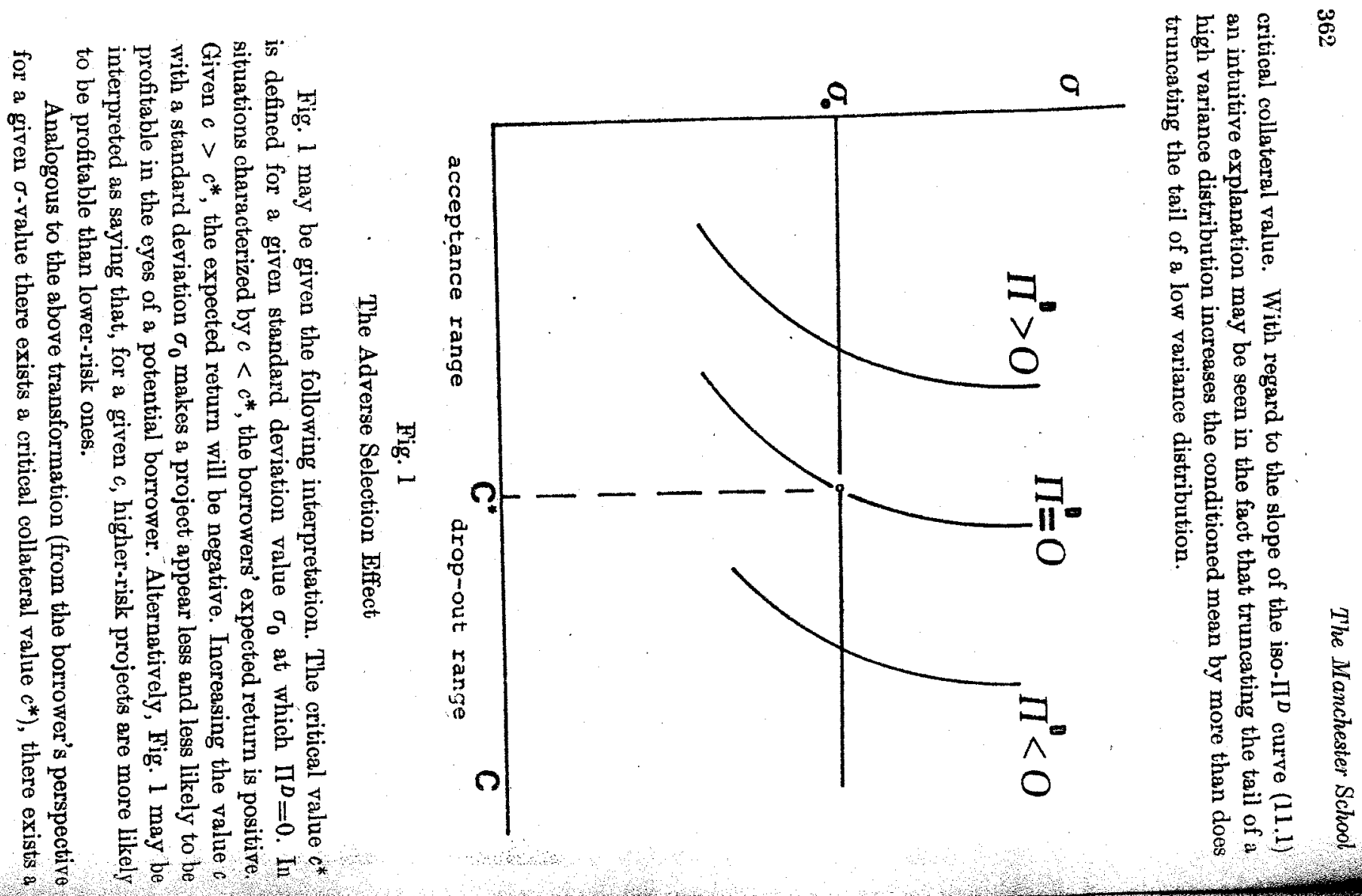

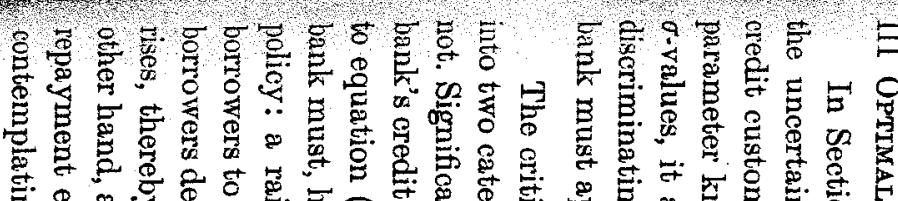

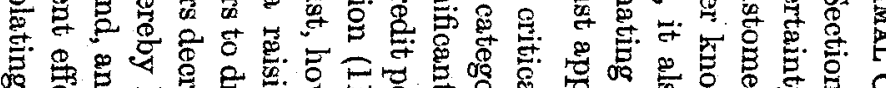

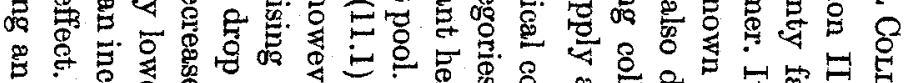
年

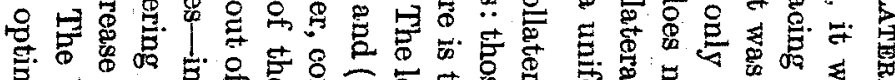
年

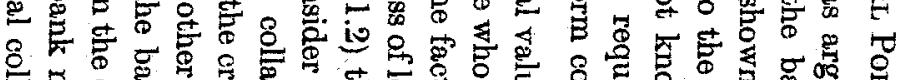
等 $-8$ 은

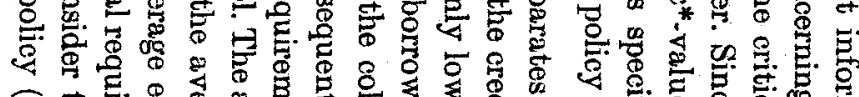



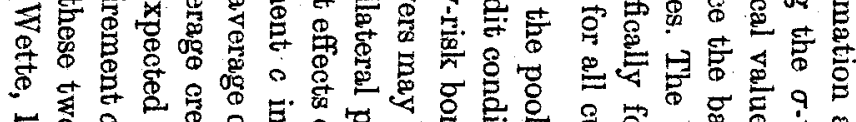



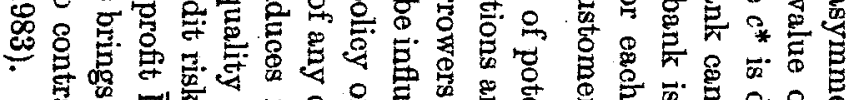

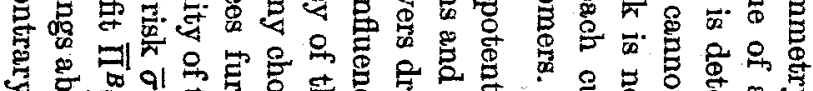

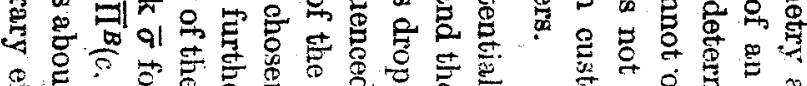

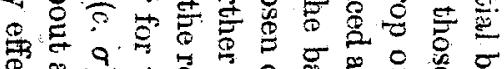

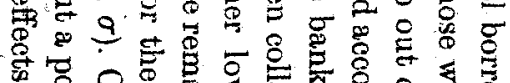

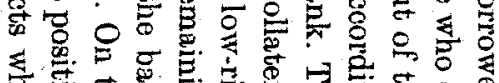

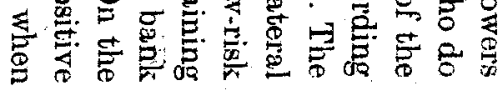

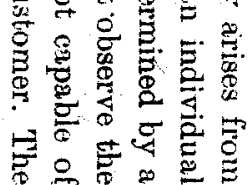

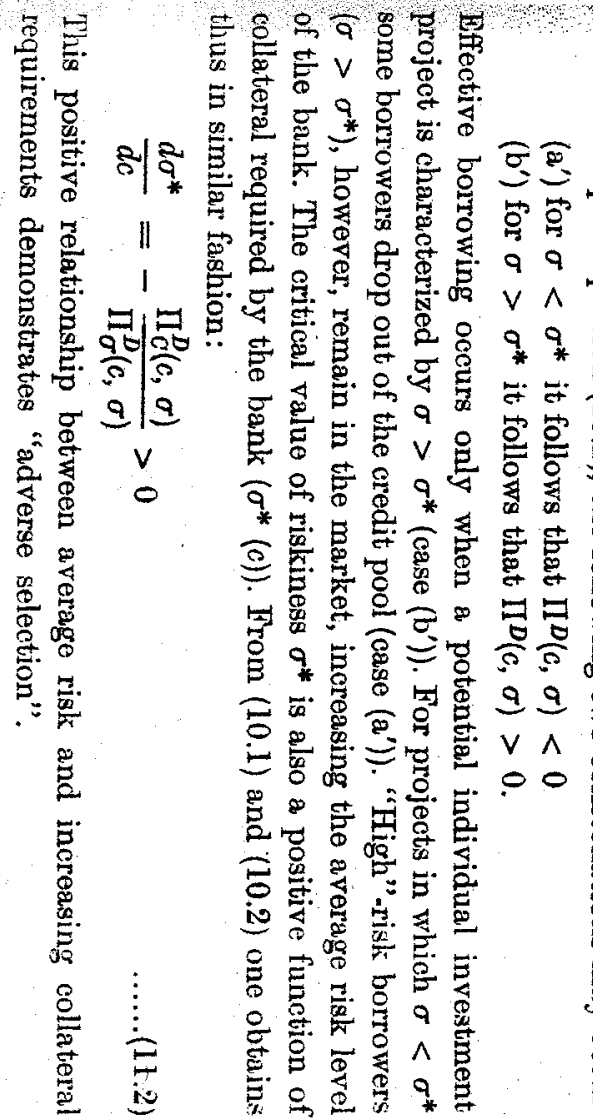


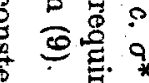



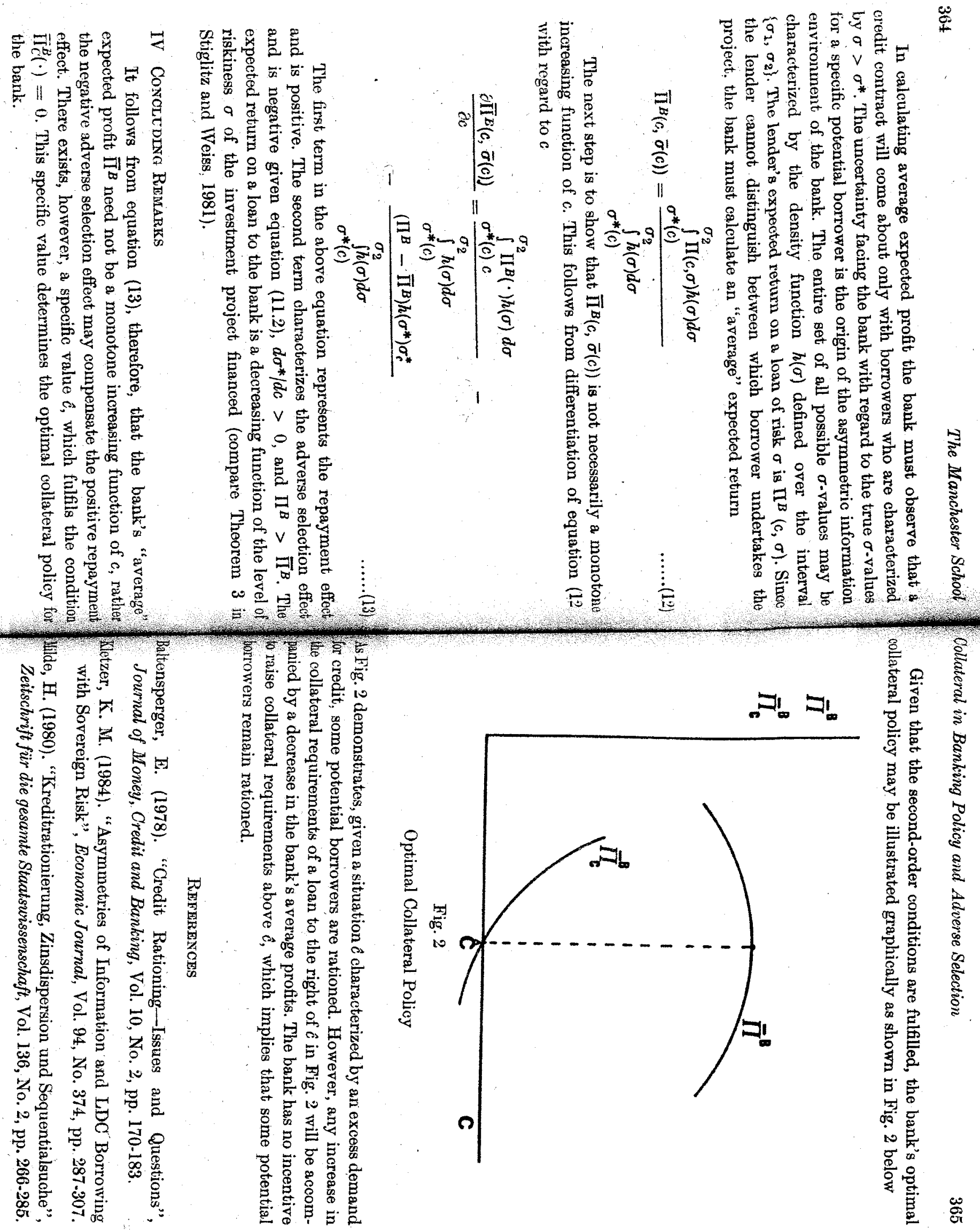


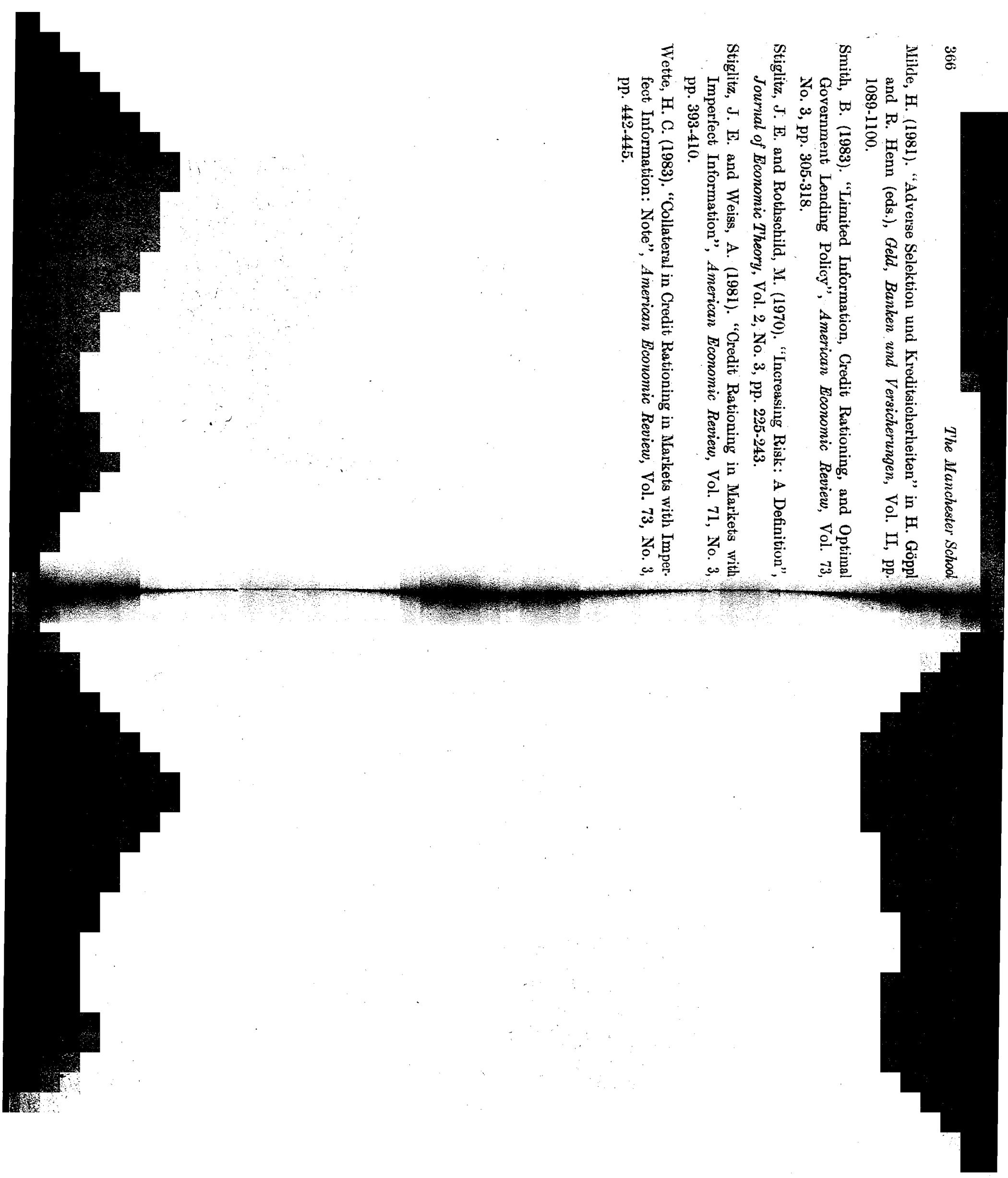

